\title{
Stresses of Coatings Based on a Solution of Expanded Polystyrene During Curing
}

\author{
Loganina VI *, Kislitsyna SN and Mazhitov YB
}

Penza State University of Architecture and Construction, Penza, Street Titov, Russia

\begin{abstract}
The purpose of the paper is to evaluate the crack resistance of a coating based on a solution of expanded polystyrene. Information is provided on the stress state of coatings based on a solution of expanded polystyrene depending on the time of curing, the thickness of the coating. It is established, that the process of curing polymer coatings passes through three stages. On the first stage of coating formation, intensive evaporation of the solvent occurs. In the second stage - after evaporative of approximately $70 \%$ of the solvent, an intensive growth of internal stresses begins. In the third stage, the concentration of the solvent is reduced to a value close to equilibrium and its evaporation rate approaches zero. Internal stresses, having reached a maximum value are stabilized. The introduction of a plasticizer in an amount of $1-4 \%$ (by volume) causes a sharp decrease in internal stresses. It is established, that internal stresses increase linearly with increasing polymer coating thickness. A mathematical model of the dependence of internal stresses on coating thickness is given.
\end{abstract}

Keywords: Coating; Internal stresses; Coating thickness; plasticizer; Expanded polystyrene

\section{Introduction}

Despite the wide range of paint-and-lacquer materials available, the range of paint coatings suitable for anticorrosive protection of building structures is relatively low.

We have developed a new paint-and-lacquer materials compositions based on the solution of expanded polystyrene wastes for the anticorrosion protection of concrete and reinforced concrete building structures [1]. To assess the crack resistance of coatings based on a solution of expanded polystyrene, it is necessary to study the stress state of coatings. Internal stresses that arise in the coatings reduce its cohesive and adhesive strength of the coating, and therefore its longevity., and, under certain conditions, can cause cracking or peeling of the coatings and a decrease in the protective properties of the coatings.

Cracking occurs when internal stresses become greater than the cohesive strength of the coatings, i. e. $\sigma>R$ [2-4]. In this regard relevant is research the internal stresses in coatings based on a solution of expanded polystyrene.

\section{Materials and Methods}

For making of polymer composites we used wastes of heatinsulating expanded polystyrene of PSB grade with density $20 \mathrm{~kg} /$ $\mathrm{m}^{3}$ (GOST 15588-70). As solvents used a mixture of acetone and gasoline A-76 in the ratio 1: 1 (solvent $\mathrm{AB}$ ). As fillers used powders of calcium fluoride. As a pigment was used chromium oxide $\mathrm{Cr}_{2} \mathrm{O}_{3}$ As the plasticizer used dibutyl phthalate.

Research of internal stresses was carried out on paint and varnish compositions with an optimum content of fillers by measuring the radius of twisting of the substrate with a polymer coating.

Measurement methods internal stress is as follows. On aluminum disk with a diameter of $120 \mathrm{~mm}$ and a thickness of $0.03 \mathrm{~mm}$ was applied to the polymer coating. On the other side of the disc, a strain gauge was affixed, the readings of which were recorded with was affixed, the readings of which were recorded with an automatic deformation meter AID-4 M.
Computations was carried out according to the formula:

$$
\sigma=2 \frac{\left(1-\mu_{1}\right) h_{2}}{h_{1}} E_{2} \varepsilon
$$

where $\mu_{1}$ - Poisson's constant of polymer composite; $h_{2} \cdot h_{1}$ - the thickness of the substrate and polymer coating; $E_{2}$-modulus of elasticity of the substrate; $\varepsilon$ - relative deformation of the substrate.

\section{Results and Discussion}

The research findings of internal stresses show that the process of curing polymer coatings passes through three stages. Figure 1 shows the kinetic curves of evaporation of the solvent (curve 1) and the growth of internal stresses (curve 2), in the process of obtaining of coatings from a solution of PPS in a mixed solvent. In its formative stage of coating formation, intensive evaporation of the solvent (about $50 \%$ ) occurs, leading to a sharp decrease in the mass of the polymer coating (section oa curve 1). In this case, insignificant internal stresses are formed in the coating, making $\sigma=0.1 \mathrm{MPa}$ (section OA of curve 2). In the second stage - after evaporative of approximately $70 \%$ of the solvent, an intensive growth of internal stresses begins (section $\mathrm{AB}$ of curve 2).

The evaporation rate of the solvent at this stage is markedly lower (section ab of curve 1). In the third stage, after $0.5 \mathrm{~h}$ of curing of the polymer coating, the concentration of the solvent is reduced to a value close to equilibrium, and its evaporation rate approaches zero (plot 6 in curve 1). Internal stresses, having reached a maximum value equal to, $=1.2 \mathrm{MPa}$, are stabilized (section BV of curve 2). Subsequently,

*Corresponding author: Loganina VI, Penza State University of Architecture and Construction, Penza, Street Titov, Russia, Tel: +7 (8412) 487476; E-mail: loganin@mail.ru

Received June 26, 2017; Accepted August 03, 2017; Published August 07, 2017

Citation: Loganina VI, Kislitsyna SN, Mazhitov YB (2017) Stresses of Coatings Based on a Solution of Expanded Polystyrene During Curing. J Appl Mech Eng 6: 280. doi: 10.4172/2168-9873.1000280

Copyright: @ 2017 Loganina VI, et al. This is an open-access article distributed under the terms of the Creative Commons Attribution License, which permits unrestricted use, distribution, and reproduction in any medium, provided the original author and source are credited. 


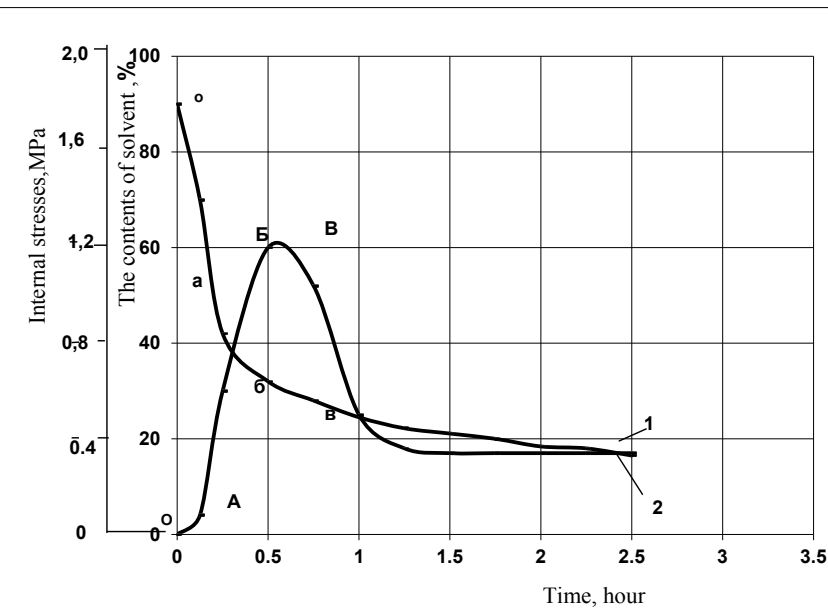

Figure 1: Time dependence of internal stresses (2) and solvent content (1) in coatings based on the solution of PPS in a mixed solvent.

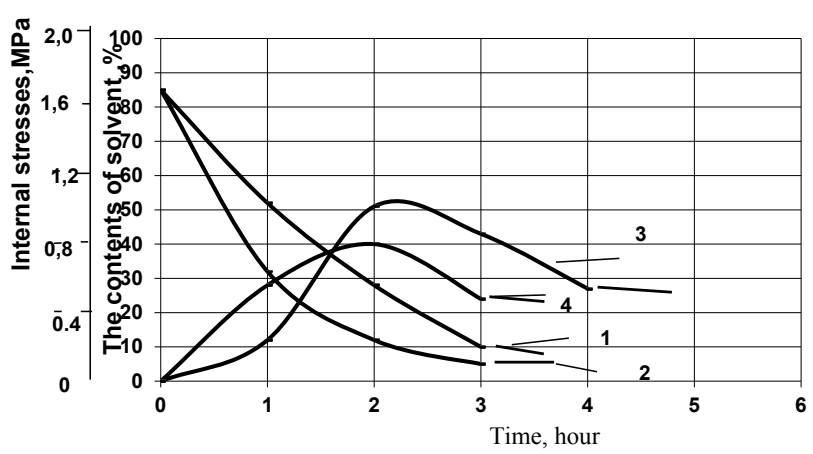

Figure 2: The time dependences of internal stresses $(3,4)$ and solvents content $(1,2)$ in coatings based on the solution of PPS in o-xylene $(1,3)$ and solvents $(2,4)$.

after approximately 3 hours of curing the coating, the internal stresses decrease to a value of $=0.32 \mathrm{MPa}$.

Internal stresses arise, principally, in the second stage i.e., sharp increase in the rigidity of the coating, and consequently of the internal stresses, begins only with the evaporation of the solvent molecules associated with the polar groups of the film-forming agent. This corresponds to the contents to a solvent content of about $70 \%$.

Figure 2 shows the time dependences of internal stresses and solvents in coatings based on a $15 \%$ solution of PPS in o-xylene (1.3) and solvents (2.4).

To obtain kinetic curves of solvent evaporation and growth of internal stresses in coatings based on the solution of PPS in o-xylene and solvent have the same character as for coatings based on a solution of PPS in a mixed solvent (Figure 2). However, the curing process of coatings with the use of a mixed solvent ends much earlier than in coatings based on solutions of PPS in o-xylene and solvent, because of the high volatility of the mixture solvent.

We carried out studies of the effect of the concentration of solutions of PPS in a mixed solvent on the magnitude and kinetics of the buildup of internal stresses.

It was found, that with an increase in the concentration of PPS solutions, the first stage of curing of the coating decreases noticeably, while the intensity of stress increase in the second stage remains practically constant. For 30\% PPS solutions, stresses occur almost immediately after the drying process begins. For 20\% and 15\% solutions, the presence of the first stage is characteristic.

The value of internal stresses with increasing concentration of the solution of expanded polystyrene decreases. Thus, for a $15 \%$ solution of PPS, the maximum value of internal stresses was $1.2 \mathrm{MPa}$, for a $20 \%$ solution the internal stresses were reduced to $1.1 \mathrm{MPa}$, and for a $30 \%$ solution of PPP it was 1.0 MPa. We were exploring of the nature of the solvent on the magnitude of internal stresses was investigated (Table 1).

The most value of internal stresses is observed in coatings obtained from solutions of PPS in o-xylene, and the smallest in coatings from solutions in a mixed solvent. The introduction of plasticizers has a great influence on internal stresses. We used polymer coatings based on a $15 \%$ solution of PPS in a mixed solvent filled with a mixture of calcium fluoride and a pigment (Figure 3).

Figure 4 shows the dependence of internal stresses $\sigma$ of polymer coatings on the content of polymer coatings on the content of plasticizer dibutyl phthalate.

The introduction of plasticizers results in lower in internal stresses in the coatings. Thus, the introduction of a plasticizer in an amount of $1-4 \%$ (by volume) causes a sharp decrease in internal stresses from 1.2 to $0.42 \mathrm{MPa}$. Further increase in the plasticizer content has little effect on the value of the stress in the coating.

The content of the plasticizer in an amount of $4 \%$ corresponds to a minimum (curve bending in Figure 4). The introduction of plasticizer to $4 \%$ results in lower in internal stresses $\sigma$, which compensates for the reduction in strength characteristics. Further introduction of the plasticizer does not reduce internal stress, but causes further weakening of the system and deterioration of the coating properties. Hence, it can be concluded that the introduction of a plasticizer more than $4 \%$ is impractical. In our further studies, the plasticizer (DBP) was introduced in an amount of $4 \%(\mathrm{v} / \mathrm{v})$.

\begin{tabular}{|l|c|}
\hline Name of solvent & Internal stresses, MPa \\
\hline O-xylene & 0.56 \\
\hline Solvent & 0.47 \\
\hline Mixed solvent & 0.32 \\
\hline
\end{tabular}

Table 1: Influence of the nature of the solvent on internal stresses plasticized coatings based on PPS.

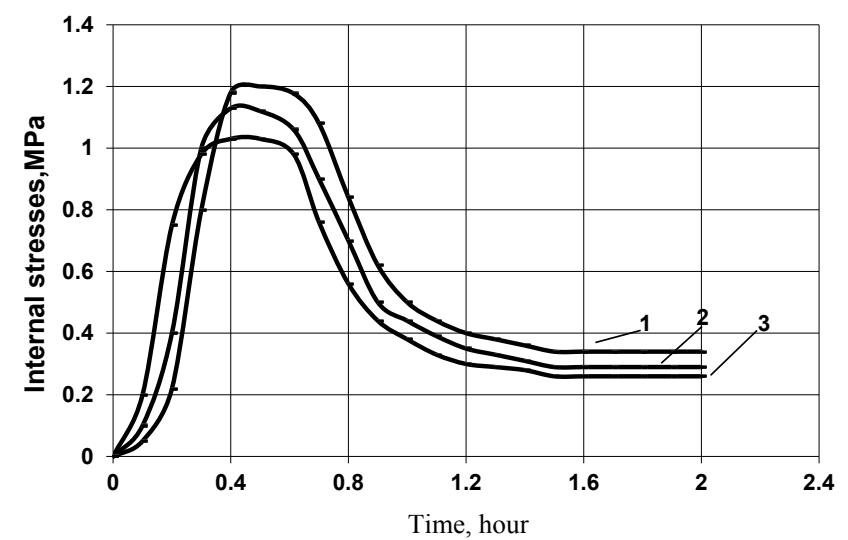

Figure 3: Dependence of internal stresses on the curing time of polymer coatings based on the solution of PPS of different concentrations: $1-15 \%$; $2-20 \% ; 3-30 \%$. 


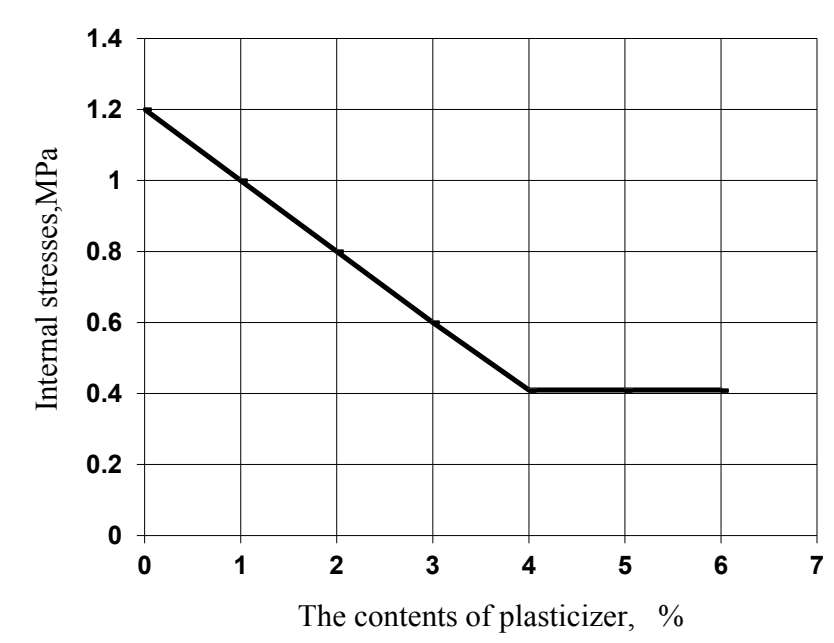

Figure 4: Dependence of internal stresses of polymer coatings based on the solution of PPS on the content of plasticizer.

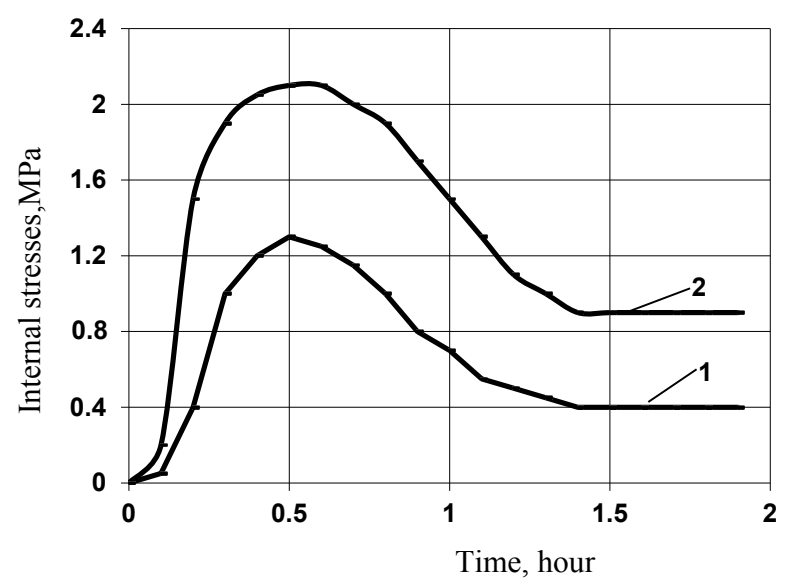

Figure 5: Time dependence of internal stresses in plasticized (1) and unplasticized (2) coatings based on the solution of PPS in a mixed solvent, filler - calcium fluoride with a pigment.

Stress internal increase in plasticized polymer coatings lags behind the growth of internal stresses in unplasticized polymer coatings (Figure 5).

In the plasticized polymer coating, the maximum internal stresses were $\sigma=2.1 \mathrm{MPa}$, and in the unplasticized polymer coating - 1.3 $\mathrm{MPa}$. Evidently, this is because the modulus of elasticity of the plasticized polymer is less than the elastic modulus of the unplasticized polymer. Thus, the modulus of elasticity of unplasticized polymer is $E=300 \mathrm{MPa}$, and that of a plasticized polymer - 50 MPa

Figure 6 shows the curves of changes in internal stresses during the curing of plasticized polymer coatings of different thickness, the filler is a mixture of calcium fluoride with a pigment.

Analysis of the experimental data shows, that as the thickness of the polymer coating increases, the maxima of the kinetic curves shift to the right, while of the kinetic curves shift to the right, while the maximum values of internal stresses increase from 1.3 to $1.42 \mathrm{MPa}$. As the coating thickness is increased, the first curing stage is reduced, and the intensity of internal stress increase in the second stage decreases noticeably.

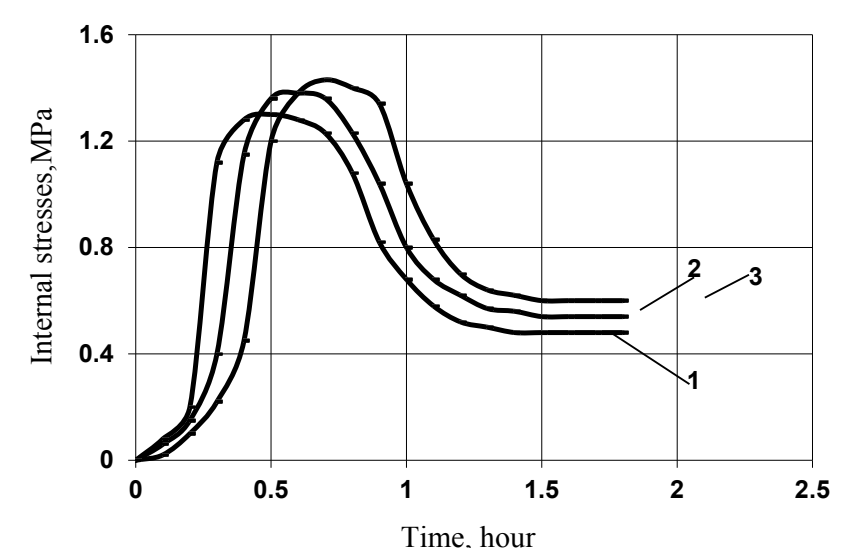

Figure 6: Dependence of internal stresses on the time of curing in plasticized coatings based on a solution of PPS of different thickness:1-0.1 mm; 2-0.2 mm; 3-0.3 mm

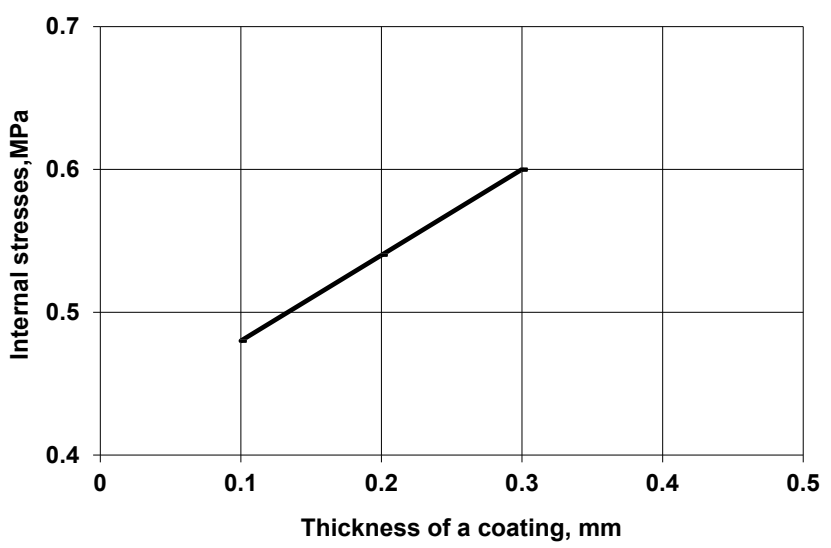

Figure 7: Dependence of internal stresses of plasticized polymer coatings based on the solution of PPS from their thickness.

This is due to a slower removal of the solvent from thick membrane. Dependence of internal stresses on the thickness of polymer coatings after $3 \mathrm{~h}$ of curing is shown in Figure 7.

With an increase in the thickness of the polymer coating from 0.1 to $0.3 \mathrm{~mm}$, internal stresses increase from 0.48 to $0.6 \mathrm{MPa}$. Analysis of the dependence of the internal stresses $\sigma$ of polymer coatings on their thickness shows, that internal stresses increase linearly with increasing polymer coating thickness and the resulting dependence is described by equation

$$
\sigma=a+b t
$$

where $a, b$ - material constants

The dependence of internal stresses in coatings based on a $15 \%$ solution of PPS on their thickness is described by the expression:

$$
\sigma=0.42+0.6 t
$$

Received calculated dependence is valid for coatings with a thickness in the range from 0.1 to $0.3 \mathrm{~mm}$. The value of internal stresses was compared with the cohesive strength of coatings of 3.8 MPa. The findings indicates that coating is crack resistance. 
Citation: Loganina VI, Kislitsyna SN, Mazhitov YB (2017) Stresses of Coatings Based on a Solution of Expanded Polystyrene During Curing. J Appl Mech Eng 6: 280. doi: 10.4172/2168-9873.1000280

\section{Conclusion}

It is established, that the values of internal stresses are less than the cohesive strength of coatings. Coatings based on a solution of expanded polystyrene are crack resistant.

\section{References}

1. Loganina VI, Kislitsyna SN (2017) Influence of scale factor on strength of polymer coatings based on waste expanded polystyrene. J Ponte 73.
2. Bartlett $F$ (1997) Precision of in-place concrete strength's predicted using core strength correction factors obtained by weighted regression analysis. Structural Safety 19: 397-410.

3. Song PS, Wu JC, Hwang S, Sheu BC (2005) Assessment of statistica variations in impact resistance of high-strength concrete and high-strength steel fiber-reinforced concrete cement. Concrete Research 35: 393-399.

4. Loganina VI (2015) The estimation of reliability of protective-decorative coverings. Contemporary Engineering Sciences 8: 91-95 